\title{
Correction to: Risk factors and outcomes of immune and non-immune causes of diffuse alveolar hemorrhage: a tertiary-care academic single-center experience
}

\author{
A. Bhushan ${ }^{1}$ (1) D. Choi ${ }^{1,2} \cdot$ G. Maresh ${ }^{1} \cdot$ A. Deodhar ${ }^{1}$
}

Published online: 26 April 2021

(c) Springer-Verlag GmbH Germany, part of Springer Nature 2021

Correction to: Rheumatology International

https://doi.org/10.1007/s00296-021-04842-2

In the original article published, the second affiliation of the author D. Choi is incorrect. The correct affiliation is "Graduate School of Dentistry, Kyung Hee University, Seoul, Korea."

The original article has been corrected.

Publisher's Note Springer Nature remains neutral with regard to jurisdictional claims in published maps and institutional affiliations.

The original article can be found online at https://doi.org/10.1007/ s00296-021-04842-2.

A. Bhushan

Bhushan@ohsu.edu

1 Oregon Health and Science University, 3181 SW Sam Jackson Park Road, Portland, OR 97239, USA

2 Graduate School of Dentistry, Kyung Hee University, Seoul, Korea 